\title{
An Overview of the U.S. GLOBEC Program
}

\author{
Michael J. Fogarty \\ NOAA/National Marine Fisheries Service. Woods Hole, Massachusetts USA
}

\author{
Thomas M. Powell \\ University of California at Berkeley. Berkeley, California USA
}

\section{Introduction}

The signature of climate-scale impacts on marine ecosystems is written in sources as diverse as the paleo-ecological record and the history of global fisheries. Analyses of sea floor sediments reveal changes in plankton communities with alteration in climate regimes, while variations in the abundance of pelagic fishes over millennia have been traced through scale deposition rates in undisturbed ocean basins. Changes in these fish communities considerably pre-date human harvesting activities for these species and point to a dominant role of climate variability and change in the dynamics of these systems. Historical documentation of catch in some of the major fisheries of Europe and Asia extends over many centuries and in these records rest clues to the waxing and waning of fish stocks in response to climate and the effects of human activities, such as fishing. The fortunes of the Hanseatic League in Medieval Europe were directly linked to trade in fishery resources, notably cod and herring, which varied with climatic conditions (Cushing, 1982; Kurlansky, 1999). The potential consequences of climate change for earth systems, the effects of other anthropogenic impacts on marine ecosystems, and the possible interaction between climate change and human activities affecting the oceans are now broadly recognized and are of vital concern.

To address these issues, U.S. GLOBEC (GLOBal Ocean ECosytems Dynamics) researchers are attempting to understand how climate change and variability will translate into changes in the structure and dynamics of marine ecosystems and in fishery production. Fishing is a 40 billion dollar per year industry in the United States and understanding the joint impact of climate and harvesting on marine populations and communities is essential for sustainability of exploited resources. U.S. GLOBEC is a multi-disciplinary research program designed by oceanographers, fishery scientists, and marine ecologists to address these issues. It is a component of the U.S. GLOBAL Change Research Program and is linked to worldwide research on this topic through International GLOBEC, a core program of the International Geosphere and Biosphere Program. U.S. GLOBEC is supported by the Division of Ocean Sciences and Office of Polar Programs of the National Science Foundation (NSF) and by the Coastal Ocean Program of the National Oceanic and Atmospheric Administration (NOAA).

The importance of understanding the role of physical environmental conditions in production processes in marine ecosystems has long been appreciated. In 1872, Spencer Fullerton Baird, first U.S. Commissioner of Fisheries, outlined a far-reaching strategy for marine research in his first report to congress. Baird recognized that

"... the temperature taken at different depths, its varying transparency, density, chemical composition, percentage of saline matter, its surface-and under-currents, and other features of its physical condition ... throw more or less light on the agencies which exercise and influence upon the presence or absence of particular fishes".

Baird further noted that studies of fish

"... would not be complete without a thorough knowledge of their associates in the sea, especially of such as prey upon them or constitute their food".

Baird advocated a multidisciplinary research plan supported by the construction of the first vessel designed specifically for oceanographic and fisheries research. The research vessel Albatross was commissioned in 1882 for this purpose and was engaged in research expeditions in the Atlantic and Pacific Oceans. The legacy and tradition of the Albatross is reflected in the U.S. GLOBEC program today; the NOAA R/V Albatross IV has played a critical role in GLOBEC studies in the Northwest Atlantic. The broad outlines of the research agenda set by Baird for understanding the role 
of physical oceanographic conditions and trophodynamics in marine productivity are carried on in GLOBEC research, as key questions have been addressed, hypotheses refined, and a fuller appreciation of the role of climate has emerged.

Interannual fluctuations in the number of individuals surviving to reach a specified size, life stage, or age-recruitment-of most marine fish and invertebrate populations are dramatic and have been linked to changes in environmental conditions. Understanding the determinants of this variability has long been a goal of biological oceanographers and fisheries scientists. The recent genesis of U.S. GLOBEC can be traced to a series of Fish Ecology Workshops held in the early 1980 s to establish an overall strategy for research on the recruitment dynamics of marine populations. A series of subsequent community workshops addressing key elements of recruitment processes culminated in the establishment in 1989 of a steering committee to foster the development of a multidisciplinary program of recruitment research. The growing recognition of the importance of climate impacts in the oceans set the recruitment problem in a broader context; i.e., understanding the role of environmental forcing along a continuum from low to high frequency change. U.S. GLOBEC studies have been designed to address recruitment issues from just this perspective.

U.S. GLOBEC studies are now underway in key locations selected to afford opportunities to examine climate effects on specific physical and biological processes in detail (Figure 1). In each location, target species thought to be sensitive to climate change have been selected for intensive study within the broader ecosystem context. GLOBEC field studies have been completed on Georges Bank (Wiebe et al., this issue) with synthesis efforts now underway. Field studies are currently in progress in the Northeast Pacific (Strub et al., this issue; Batchelder et al., this issue; Weingartner et al., this issue) and the Southern Ocean (Hofmann et al., this issue). The critical issue of elucidating the climate connection in GLOBEC studies as a whole is reviewed by Mantua et al., (this issue). This special issue is intended to provide a status report of the U.S. GLOBEC Program at mid-life, to highlight emerging findings and accomplishments to date, and to point to future research directions.

\section{Climate Change and Marine Ecosystems}

Climate change will fundamentally alter oceanographic structures and features, with direct implications for marine ecosystems and human societies (Everett et al., 1995; McLean et al., 2001). Climate change predictions consistently indicate increases in atmospheric temperatures and regional changes in precipitation patterns (McCarthy et al., 2001). Temperature changes are expected to be greatest at higher latitudes. This differential warming is expected to result in a reduction in latitudinal temperature gradients that may result in changes in the intensity of global and local wind fields. Precipitation is also expected to increase at higher latitudes.

Oceanographic features including currents, fronts, upwelling and downwelling zones and ice cover in

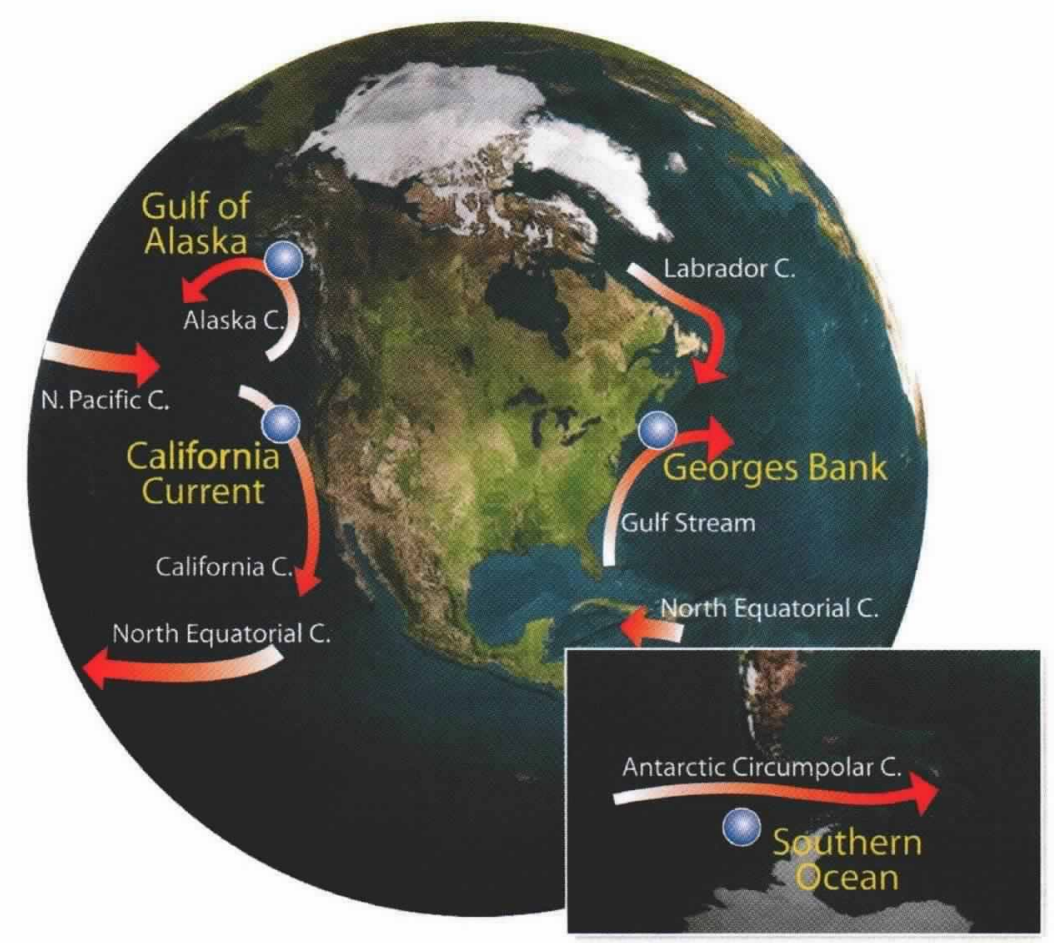

Figure 1. Location of U.S. GLOBEC study sites on Georges Bank in the Northwest Atlantic; the Coastal Gulf of Alaska and the California Current in the Northeast Pacific; and the Southern Ocean in the vicinity of the western Antarctic Peninsula. These study sites are affected by major ocean currents including a western boundary current (the Gulf Stream), an eastern boundary current (the California (urrent), buoyancy-driven currents (Alaska Current, Labrador Current) and circumpolar current system (Antarctic Circumpolar Current). 


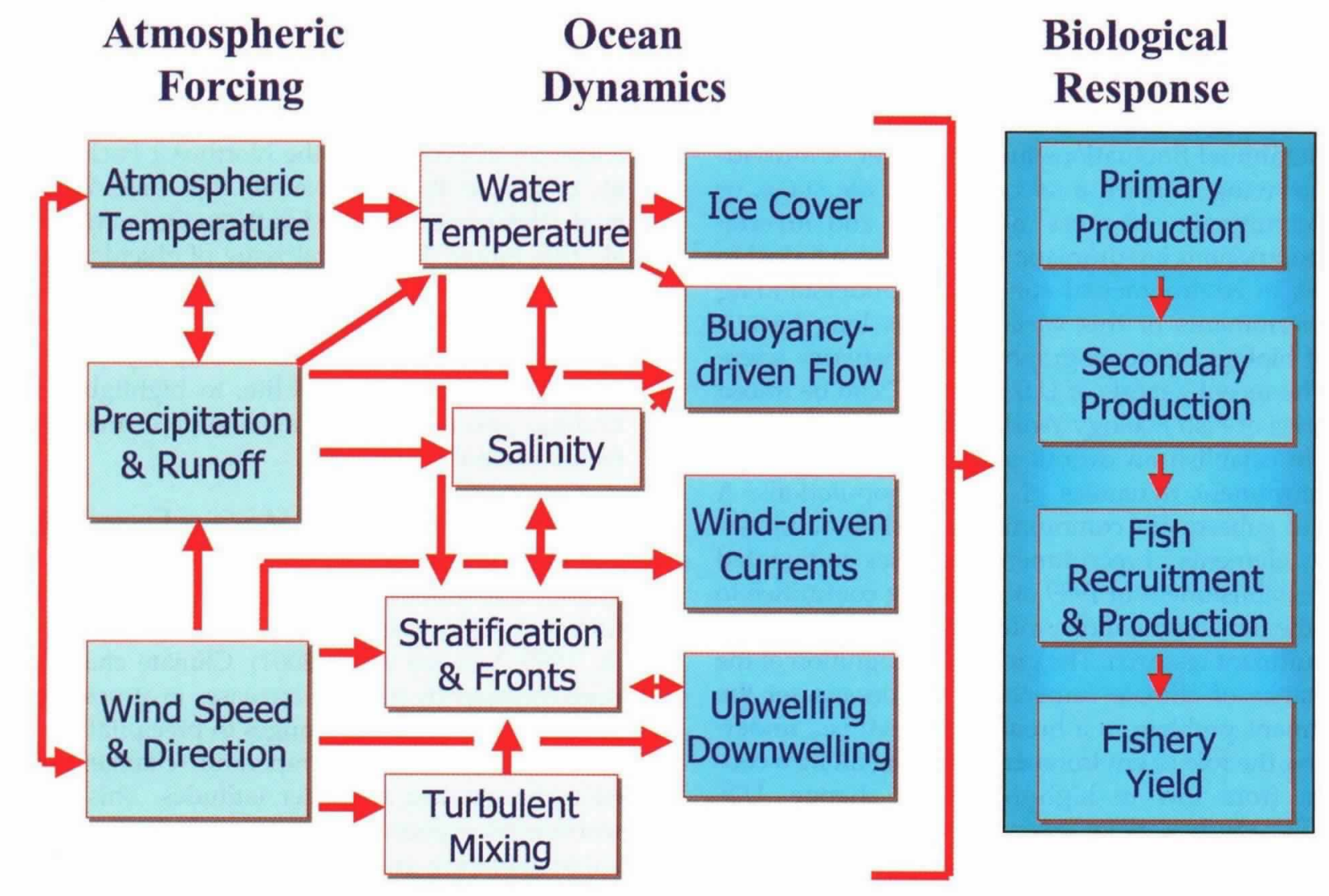

Figure 2. Interactive pathways between changes in atmospheric forcing, ocean dynamics, and biological response in production processes. Changes in atmospheric temperature, precipitation, and winds will affect stratification, buoyancy-driven flows, upwelling/downwelling, sea ice and other factors. These will potentially affect production at all trophic levels.

polar regions, will be strongly influenced by these variations in temperature, salinity, and winds. Some of the potential pathways for atmospheric effects on oceanic dynamics and biological response are depicted in Figure 2. These changes will be manifested on scales ranging from the small spatial and temporal scales characteristic of turbulent mixing processes to those of the deep ocean circulation with global-scale changes occurring over millennia. Tracking processes occurring on this spectrum of spatial and temporal scales is critical to understanding the potential effects of global climate change on marine populations and ocean ecosystems.

The projected changes in the physical geography of the sea under global climate change hold important implications for marine populations, communities, and ecosystems. For example, increased stratification due to increased temperature and or freshwater inputs can affect nutrient exchange and primary production (e.g. Mann and Lazier, 1996). Reductions in available nutrient levels and possible changes in the timing and intensity of phytoplankton blooms will have direct effects on grazers, particularly microzooplankton species that comprise the dominant consumers of phytoplankton and on macrozooplankton preying on smaller zooplankton. Many fish species in turn depend on microzooplankton and larger zooplankton species as a major food source. These factors affect the growth and survival of fishes and, ultimately, recruitment and yield (Figure 2). In addition to changes in vital rates of marine species, changes in community composition can be expected.

Shifts in distribution of marine populations can be expected with increasing water temperatures (e.g. Frank et al., 1990; Murawski, 1993; Holbrook et al., 1997; Welch et al., 1998). In general, poleward shifts in distribution can be anticipated for many taxa, although changes in depth distribution may also occur. Changes in distribution with respect to latitude or depth will affect the availability of fish and invertebrate species to regional fisheries, in some instances markedly changing the community structure and the character of these fisheries.

Temperature plays a dominant role in the physiology of zooplankton and fish species, controlling rates of growth and metabolic processes. For fish, optimal temperatures for growth result in rapid transition 
through vulnerable periods during the early life history. Whether this translates into increased survival rates depends on other temperature-dependent phenomena including metabolic demands, activity levels and associated predation risk.

Increases in temperature will result in melting of sea ice in polar and subpolar regions with direct effects on the input of freshwater into these systems. These shifts will result in changes in sea level, salinity and in buoyancy-driven flow and stratification. In addition, melting of sea ice will result in a loss in critical habitat for marine mammals, seabirds and other species that use ice shelves and floes as important habitats.

Changes in regional precipitation patterns and in ice and snow melt will alter freshwater inputs to coastal systems. Increased runoff will intensify baroclinic coastal currents that are important for dispersal of marine organisms. Changing patterns of runoff from land will also alter the input of nutrients, affecting productivity of these coastal locations. Many marine organisms exhibit distinct salinity tolerance levels and it is anticipated that these changes will contribute to overall changes in distribution patterns of marine species.

In addition to effects on stratification, changes in wind intensity will affect the strength of wind-driven currents, turbulent mixing processes, and upwelling and downwelling. Wind-driven currents play a major role in the redistribution of heat in the oceans and are critical for dispersal for many marine organisms. Turbulent mixing is thought to increase the contact rates between zooplankton and their prey (Rothschild and Osborn, 1988). As turbulence increases however, the probability of successful prey capture declines. Thus, the probability of feeding success is domeshaped with a maximum at intermediate levels of wind-speed and turbulence.

Bakun (1990) hypothesized that the temperature differential between land and sea will intensify under global warming, leading to an intensification of alongshore winds and an increase in upwelling in some areas. Bakun provided empirical evidence for an increase in alongshore wind stress (and a derived upwelling index) over the last five decades. It has been also suggested, however, that the projected reduction in the latitudinal gradient of temperature due to enhanced warning in higher latitudes will result in a lessening of wind fields in general and an overall reduction of upwelling (e.g. Gucinski et al., 1990).

Changes in regional wind fields will result in alteration in the strength of downwelling in some systems, resulting in changes in pathways of nutrient exchange and regeneration. Intensification of onshore winds can be expected to increase downwelling in these systems, possibly resulting in a reduction of available nutrients.

\section{U.S. GLOBEC Study Sites and Target Species}

Consideration of the probable impacts on ocean dynamics of global climate change (described above) have guided the choice of U.S. GLOBEC study sites and processes for study (Table 1). U.S. GLOBEC study sites have also been selected based on the availability of previous studies in each region, thus providing both a basis for formulation of key hypotheses and a broader temporal context for interpretation of new process-oriented and observational research. The regions chosen for study (Table 1) include a bank system with retentive circulation (Georges Bank), an eastern-boundary current system (California Current), a shelf system dominated by strong baroclinic flows (Coastal Gulf of Alaska), and an ice-dominated high latitude system (Southern Ocean).

Georges Bank is a highly productive submarine plateau with a distinctive anticyclonic circulation pattern driven by strong rotary tidal currents (Wiebe et al., this issue). Georges Bank is located in a faunal transition zone and changes in temperature can be expected to alter species composition of planktonic and nektonic organisms. Distinct production regimes are associated with the well mixed and stratified regions of the Bank. A change in the position of the tidal mixing front on the crest of Georges Bank and an overall reduction in the extent of the well-mixed area is possible with increased temperatures (Frank et al., 1990).

Georges Bank will also be influenced by possible changes in both wind- and buoyancy-driven current systems. If changes in the position and intensity of the Gulf Stream occur, the frequency of occurrence and/or persistence of meanders and warm core rings will be affected. Ring events strongly impact advection and loss of biota from the bank and recruitment of some fish populations is inversely related to the frequency of occurrence of warm core rings. Georges Bank is also affected by the Labrador current, a buoyancy-driven system. The southerly extent of Labrador Sea Water (LSW) is related to ice conditions and melting in the Arctic (Wiebe et al., this issue) and pronounced alteration of temperature and salinity characteristics of the bank have accompanied intrusions of LSW during the GLOBEC study period.

Upwelling and downwelling processes are critical features of the production dynamics of the California Current (Strub et al., this issue; Batchelder et al., this issue). Changes in wind fields off Oregon and California are expected to affect upwelling, with cascading effects on overall levels of nutrients impacting food web dynamics. Changes in temperature, precipitation, and winds will also affect stratification in this region. McGowan et al. (1998) attributed long term declines in zooplankton populations in the California Current to increased water temperatures, that resulted in an intensification of stratification and an overall lowering of mixing and nutrient regeneration in the upper water column. Because zooplankton are a major food source for fishes, declines in secondary production may be linked to declines in fish production Changes in cross-shelf exchange with changes in flow fields will also affect the probability of retention of 
organisms on the continental shelf, presumably affecting overall survival rates.

In the Coastal Gulf of Alaska, increases in precipitation and temperature will alter freshwater runoff patterns with resulting changes in the intensity of the Alaska Coastal Current. Changes in wind patterns will also affect downwelling in this region. Increases in stratification are anticipated in the Coastal Gulf of Alaska with increases in precipitation and runoff. Freshwater inputs are the dominant factor in stratification in these waters (Weingartner et al., this issue). It has been hypothesized that changes in productivity in the North Pacific Ocean are linked to changes in the strength of the Aleutian Low Pressure System (Polovina et al., 1995; Mantua et al., this issue). In the coastal Gulf of Alaska, a reduction in the mixed layer depth and a concentration of phytoplankton in the photic zone resulted in higher primary production levels during periods characterized by an intensified Aleutian Low. Conversely, with a deepening of the mixed layer, phytoplankton cells can be driven into zones in which light is limiting, with a resulting reduction in productivity. Variations in mixed layer depth related to winds have been linked to changes in zooplankton abundance (Brodeur and Ware, 1992) and salmon production
(Mantua et al., 1997).

U.S. GLOBEC studies in the Southern Ocean during the austral winter afford special opportunities to study the effects of sea ice dynamics on polar ecosystems (Hofmann et al., this volume). This system also offers opportunities for study of a relatively simple food web with krill as a keystone species. GLOBEC researchers are investigating the importance of retentive circulation features in the vicinity of Marguerite Bay in recruitment processes of krill (Hofmann et al., this issue). As in the other GLOBEC study regions, the critical role of stratification in the production dynamics of the system is of central importance.

Target species in U.S. GLOBEC studies are selected for their ecological importance, their likely sensitivity to climate change, and (for some) their economic importance. In each regional study, zooplankton species are targeted for their importance in regional food webs (Table 1). Calanoid copepods, dominant members of regional zooplankton assemblages, have been selected as target organisms in the Atlantic and Pacific. Euphausiids of the genera Euphausia and Thysanoessa have been selected for study in the Northeast Pacific. These species play a critical role in food web dynamics. Antarctic krill, E. superba, also sup-

Table 1. U.S. GLOBEC Study regions, system types, target species, and physical processes examined.

\begin{tabular}{|c|c|c|c|c|}
\hline & $\begin{array}{l}\text { NW Atlantic } \\
\text { Georges Bank }\end{array}$ & $\begin{array}{l}\text { NE Pacific } \\
\text { California Current }\end{array}$ & $\begin{array}{l}\text { NE Pacific } \\
\text { Coastal Gulf } \\
\text { of Alaska }\end{array}$ & $\begin{array}{l}\text { Southern Ocean } \\
\text { West Antarctic } \\
\text { Peninsula }\end{array}$ \\
\hline System Type: & $\begin{array}{l}\text { Bank with Gyre } \\
\text { Circulation }\end{array}$ & $\begin{array}{l}\text { Eastern Boundary } \\
\text { Current with Upwelling }\end{array}$ & Buoyancy-Driven Flow & Ice-Dominated \\
\hline $\begin{array}{l}\text { Target } \\
\text { Organisms: } \\
\text { Zooplankton }\end{array}$ & $\begin{array}{l}\text { Calanus finmarchicus } \\
\text { Pseudocalanus sp. } \\
\text { Gadus morhua } \\
\text { Melanogrammus } \\
\text { aeglefinus }\end{array}$ & $\begin{array}{l}\text { Calanus species } \\
\text { Euphausia pacifica } \\
\text { Thysanoessa spinifera } \\
\text { Oncorhynchus kisutch } \\
\text { O. tshawytscha }\end{array}$ & $\begin{array}{l}\text { Neocalanus species } \\
\text { Euphausia pacifica } \\
\text { Thysanoessa spinifera } \\
\text { Thysanoessa inermis } \\
\text { Thysanoessa raschii } \\
\text { Oncorhynchus gorbuscha }\end{array}$ & Euphausia superba \\
\hline $\begin{array}{l}\text { Physical } \\
\text { Processes } \\
\text { Examined: }\end{array}$ & $\begin{array}{l}\text { Stratification } \\
\text { Transport/Retention } \\
\text { Cross-Front-Exchange }\end{array}$ & $\begin{array}{l}\text { Stratification } \\
\text { Cross-Shelf-Transport } \\
\text { Upwelling/Downwelling } \\
\text { Cross-Shelf-Transport }\end{array}$ & $\begin{array}{l}\text { Stratification } \\
\text { Cross-Shelf Transport } \\
\text { Downwelling } \\
\text { Buoyancy Flow }\end{array}$ & $\begin{array}{l}\text { Sea Ice Dynamics } \\
\text { Stratification } \\
\text { Transport/Retention }\end{array}$ \\
\hline
\end{tabular}




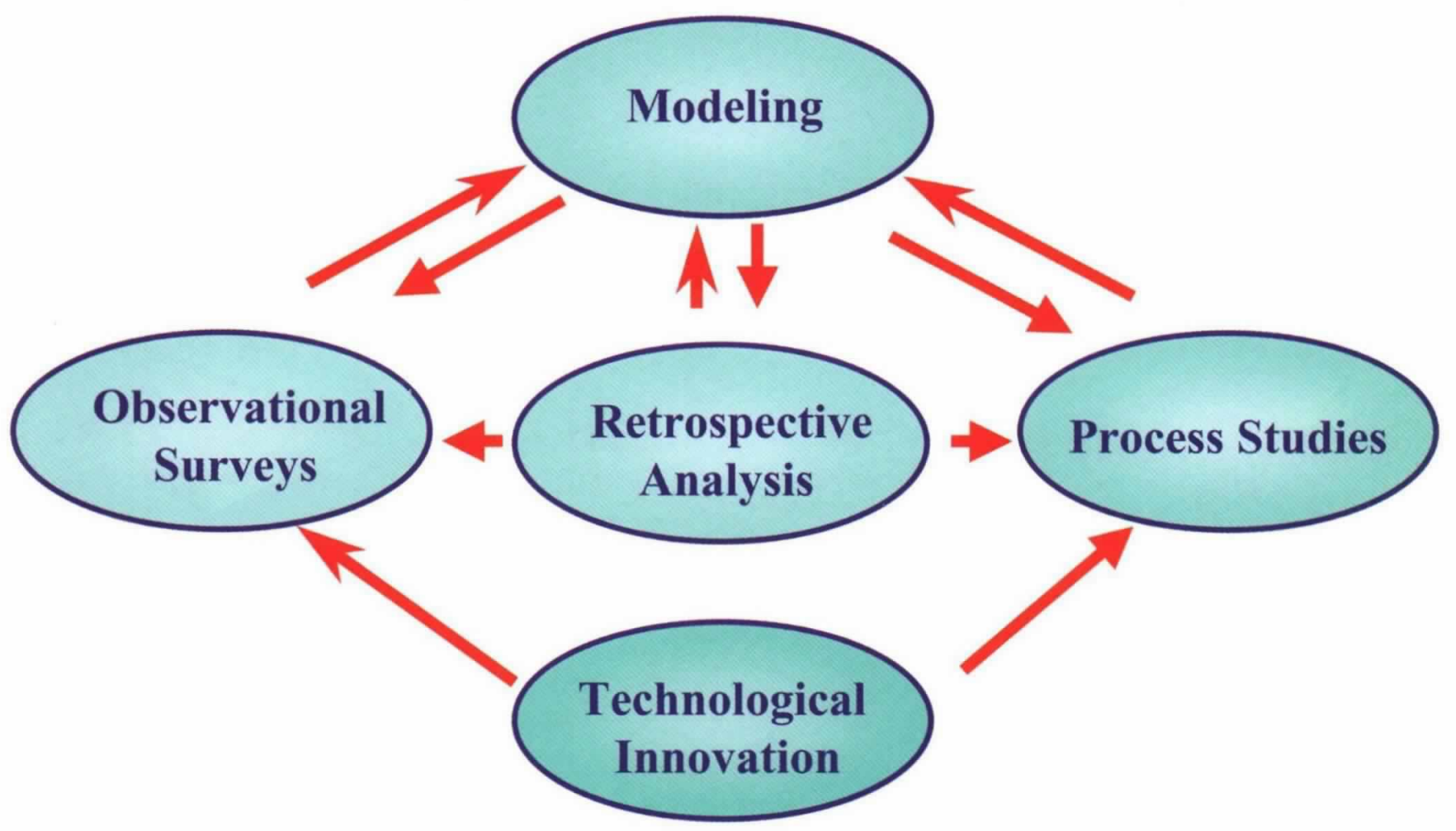

Figure 3. GLOBEC research strategy entailing the application of technological innovation, process-oriented studies, observation survey programs, retrospective analysis, and modeling.

port an important international commercial fishery in the Southern Ocean.

In the Northwest Atlantic and in the Northeast Pacific, fish species have been selected for special emphasis because of their critical importance to the fisheries of these regions. In the northeast, Atlantic cod (Gadus morphua) and haddock (Melanogrammus aeglefinus) have been mainstays of the commercial fisheries for centuries but have been depleted by overharvesting. Both species are near the southern extent of their range on the Georges Bank and are therefore expected to be sensitive to climate change.

Salmon production in the North Pacific has undergone multidecadal changes linked to changes in the Pacific Decadal Oscillation, (Mantua et al., 1997; Mantua et al., this issue). GLOBEC target species include coho (Oncorhyncus kisutch) and chinook (O. tshawytscha) salmon in the California Current system, and pink salmon $(O$. gorbuscha) in the Gulf of Alaska.

Abundance and recruitment of krill has been linked to sea ice extent (Loeb et al., 1997) with higher krill levels expected with enhanced ice cover. The undersurface of the ice is a critical habitat for small krill. During periods of reduced ice extent, ecosystem changes have been documented with a dominance of salps in the pelagic system.

\section{The GLOBEC Research Strategy}

From its inception, the GLOBEC research strategy has entailed an inter-related set of elements: modeling, process-oriented studies, an observational survey component, retrospective analysis, and technological innovation (Figure 3). The development of both conceptual and formal analytical models has served to frame the questions to be asked and the parameters to be measured. Models provide the principal synthetic and integrative tools for interpretation and prediction. Process studies measure key variables required for models and are designed to provide a mechanistic understanding of critical inter-relationships in the systems under investigation. Observational survey programs provide a broader spatial and temporal context for interpretation of process studies and measurements taken on finer spatial scales. In the Georges Bank region, these are desig- 


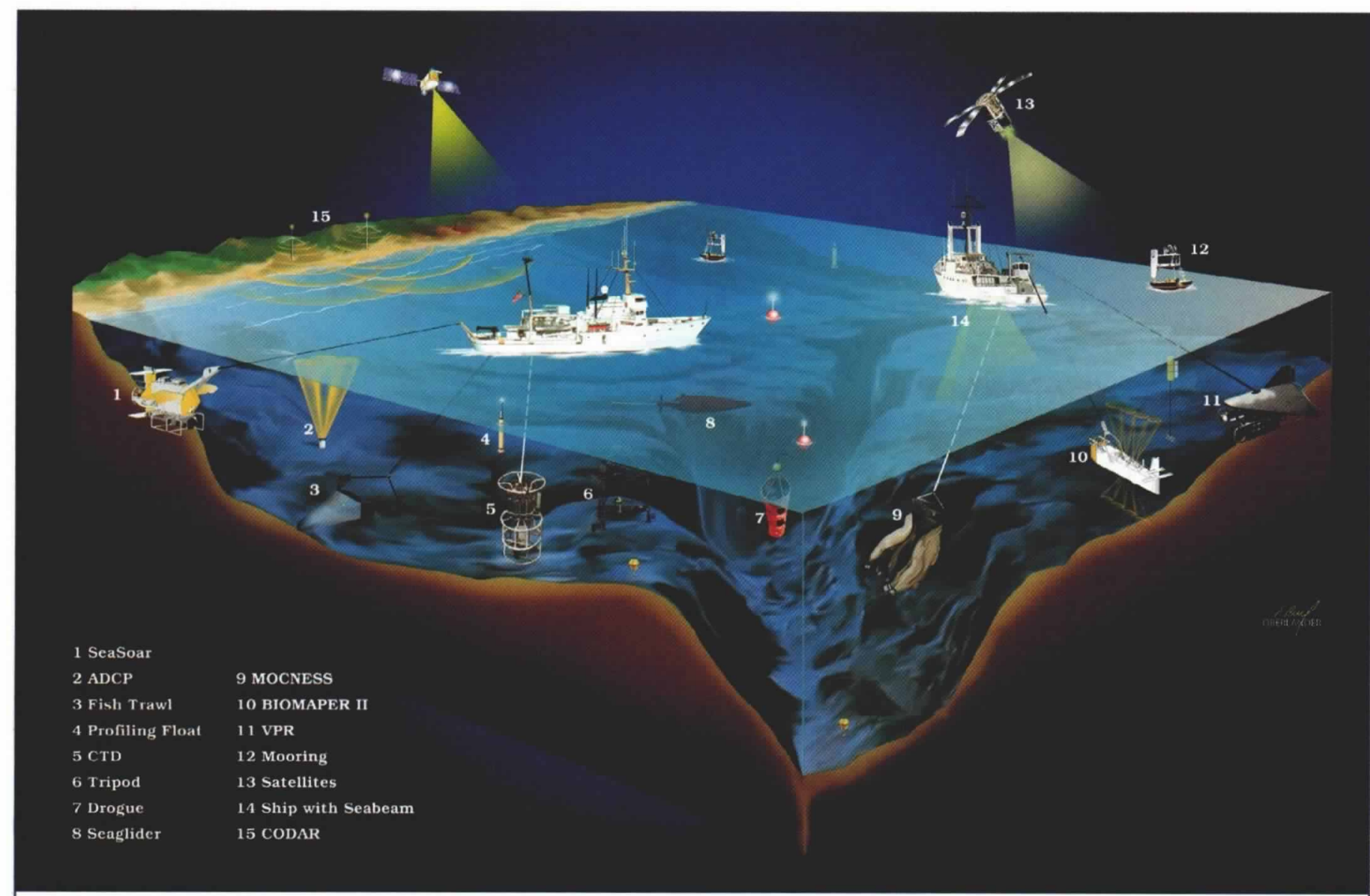

Figure 4. Research platforms and instruments used in U.S. GLOBEC including SeaSoar, ADCP, fish trawls, profiling floats, CTD, moored device, drifters, autonomous vehicles, electronic net systems, BIOMAPER, videoplankton recorder (VPR) satellite systems, and high frequency radar.

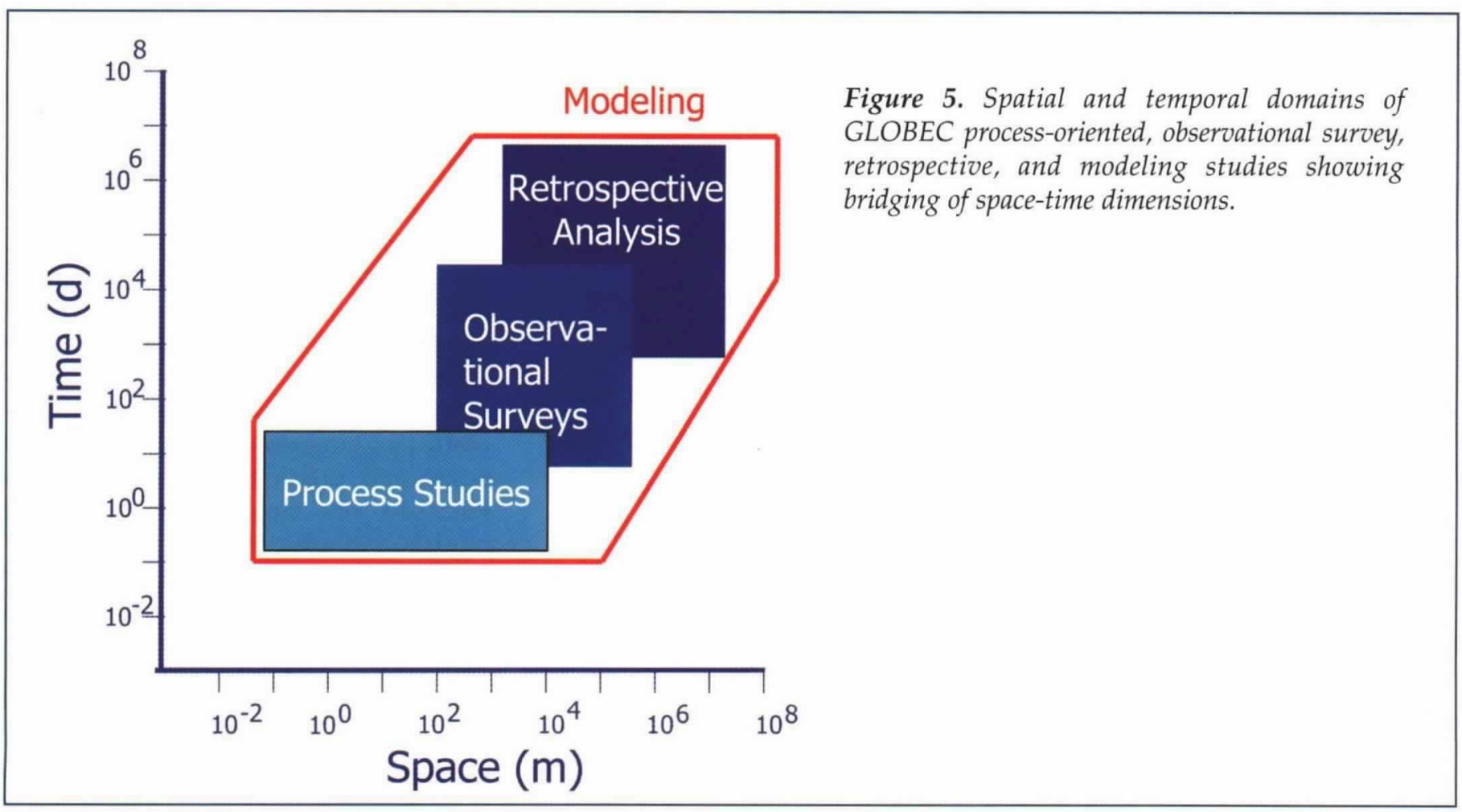




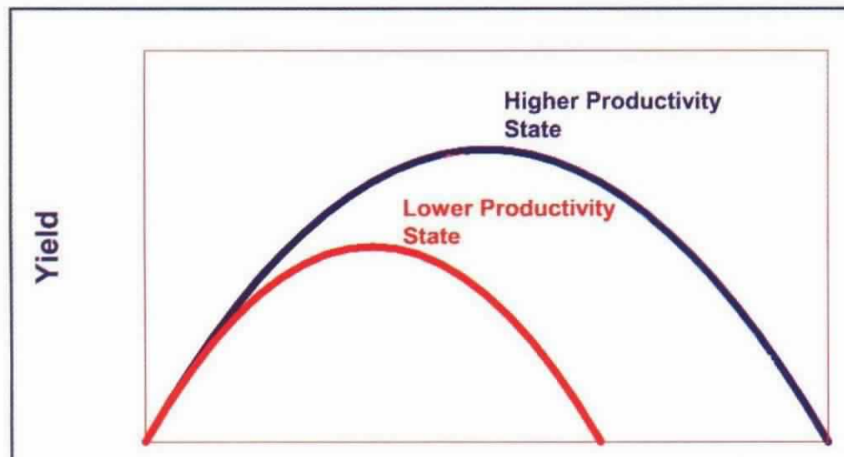

Fishing Intensity

Figure 6. Expected yield under different climate regimes affecting production of exploited populations.

nated Broad-scale Surveys (Wiebe et al., this issue) while in the Northeast Pacific, the observational component includes both the Long-Term Observation Program (LTOP) and the Mesoscale Program (currently in place in the California Current and under consideration for the Coastal Gulf of Alaska). Retrospective analyses provide yet a broader window in time (and in some instances, space) for the interpretation of change in the systems under investigation.

The chronic under-sampling of the seas presents a formidable challenge to understanding the determinants of change in marine ecosystems. It was recognized that GLOBEC could only succeed if new tools were utilized to enhance spatial and temporal sampling of physical properties and biological characteristics of these systems. Newly emerging technologies, coupled with standard sampling tools, have been employed in GLOBEC programs to address this need (Figure 4). Satellites, high frequency radar, moored instruments, autonomous vehicles, floats and drifters, and ship-borne sampling devices ranging from netsampling systems to multi-instrument packages including hydroacoustic and optical sensors have been variously employed in the GLOBEC study areas as components of the observational program, and process studies.

At the heart of understanding and predicting the effects of climate change on marine ecosystems is the development of research strategies that effectively bridge a broad spectrum of space-time scales relevant to individual organisms, populations, and ecosystems. At the organismal level, the relevant space-time scales can change dramatically throughout the life history. For many fish species which change in size over several orders of magnitude throughout the life cycle, the ambit ranges from fine scale processes occurring over centimeters and seconds at the larval stage, to hundreds or thousands of kilometers and decades for adults of highly migratory species. Populations of marine organisms can occupy areas of tens of thousands of square kilometers or more and persist for millennia.

The GLOBEC strategy of nested process studies, mesoscale observations, retrospective analysis and modeling provides one avenue to bridging the critical scales in space and time (Figure 5). The observational survey programs are essential to interpreting the process-oriented studies while also providing measurement of key variables required for physical and biological models. The expected time frame for GLOBEC field studies is short relative to that relevant to climate-scale processes, and utilizing longer time-series measurements is critical. Retrospective analysis of physical and biological variables provides one approach to understanding how observed levels of variability in GLOBEC field studies fit within expected levels on broader time horizons. Because ocean ecosystem properties are expected to exhibit a reddened spectrum, this understanding is essential.

\section{Box 1 - U.S. GLOBEC Developmental History}

1980 Fish Ecology I Workshop

1982 Fish Ecology II Workshop

1983 Fish Ecology III Workshop

1985 National Academy of Sciences Working Group on Recruitment

1988 Wintergreen GLOBEC Workshop

1989 U.S. GLOBEC Scientific Steering Committee formed

1991 Initial Modeling Efforts Funded

1992 Georges Bank Pilot Program Started

1995 Georges Bank Field Program Started

1997 Northeast Pacific Field Programs Started

2001 Southern Ocean Field Program Started

\section{Management Implications}

Factors affecting the productivity of marine resources and ecosystem structure must be directly accounted for in any fishery management strategy. Levels of sustainable yield and optimal levels of exploitation are both directly tied to the state of the environment and its effects on productivity of marine populations. The effects of exploitation and environmental change can be synergistic. In particular, environmental changes that result in an overall reduction in the productivity of a marine resource can result in the decline or collapse of a population under levels of exploitation that are sustainable under more 
favorable environmental conditions. Persistent shifts in productivity levels on longer time scales in particular must be taken into consideration in the development of management approaches. The multidecadal shifts in productivity in the Pacific provide an important indication of the types of changes that can occur and their effects on fishery yields.

In general, the yield from a fishery will be highest at some intermediate level of fishing pressure for populations governed by some form of compensatory response. Environmental conditions will affect both population levels and the resulting yields. If persistent shifts in environmental conditions occur on decadal time scales, we can envision a family of production curves. If the changes in production characteristics change in a way that is independent of population density, relationships such as those depicted in Figure 6 will hold. Notice that not only is the expected yield reduced under less favorable environmental conditions, the level of fishing pressure that can be sustained by the population is lower. The peak of the lower curve occurs at a lower level of fishing pressure and the population will collapse at fishing intensities that are sustainable under more favorable environmental conditions. It is clear that we must consider concepts such as maximum sustainable yield as being directly linked to prevailing environmental conditions. GLOBEC studies are contributing directly to an understanding of production dynamics in response to physical forcing and will play a major role in the development of a more dynamic concept of sustainability in a changing world.

This is U.S. GLOBEC contribution Number 229.

\section{References}

Bakun, A., 1989: Global climate change and intensification of coastal ocean upwelling. Science, 247, 198-201.

Brodeur, R.D. and D.M. Ware. 1992: Interannual and interdecadal changes in zooplankton biomass in the subarctic Pacific Ocean. Fish. Oceanogr., 1, 32-38.

Cushing, D.H., 1982: Climate and Fisheries. Academic Press, London, 373pp.

Frank, K.T., R.I. Perry and K.F. Drinkwater, 1990: Predicted response of Northwest Atlantic invertebrate and fish stocks to $\mathrm{CO}_{2}$-induced climate change. Trans. Am. Fish. Soc., 119, 353-365.

Everett, 1995: Fisheries. In: Climate Change 1995: Impacts, Adaptations and Mitigation of Climate Change: Scientific-Technical Analyses. R.T Watson, M.C. Zinyowera, R.H. Moss, and D.J. Dokken, eds., Contribution of Working Group II to the Second Assessment Report of the Intergovernmental Panel on Climate Change, 511-538.

Gucinski, H., R.T. Lackey and B.C. Spence, 1990: Global climate change: policy implications for fisheries. Fisheries, 15, 33-38.

Holbrook, S.J., R.J. Schmitt and J.S. Stephens, Jr., 1997:
Changes in an assemblage of temperate reef fishes associated with a climate shift. Ecol. Appl., 7, 1299-1310.

Kurlansky, M., 1999: Cod: A biography of the fish that changed the world. Walker and Co., New York.

Loeb, V., V. Siegel, O. Holm-Hansen, R. Hewitt, W. Fraser, W. Trivelpiece and S. Trivelpiece, 1997: Effects of sea ice extent and krill or salp dominance on the Antacrctic food web. Nature, 387, 897-900.

Mann, K.H. and J.R.N. Lazier, 1996: Dynamics of Marine Ecosystems: Biological-Physical Interactions in the Oceans, 2nd Edition. Blackwell Science, Cambridge.

Mantua, N.J., S.R. Hare, Y. Shang, J.M. Wallace and R.C. Francis, 1997: A Pacific interdecadal climate oscillation with impacts on salmon production. Bull. Am. Met. Soc., 78, 1069-1079.

McCarthy, J.J., O.F. Canziani, N.A. Leary, D.J. Dokken and K.S. White, eds., 2001: Climate Change 2001: Impacts, Adaptation, and Vulnerability. Cambridge University Press.

McClean, R.F., A. Tsyban, V. Burkett, J.O. Codignotti, D.L. Forbes, N. Mimura, R.J. Beamish and V. Ittekkot, 2001: Coastal zones and marine ecosystems. In: Climate Change 2001: Impacts, Adaptation, and Vulnerability. J.J. McCarthy, O.F. Canziani, N.A. Leary, D.J. Dokken and K.S. White, eds., Cambridge University Press, 343-379.

McGowan, J.A., D.R Cayan and L.M. Dorman, 1998: Climate-ocean variability and ecosystem response in the northeast Pacific. Science, 281, 210-217.

Murawski, S.A., 1993: Climate change and marine fish distributions: Forecasting from historical analogy. Trans. Am. Fish. Soc., 122, 657-658.

Polovina, J.J., G.T. Mitchum and G.T. Evans, 1995: Decadal and basin scale-variation in mixed layer depth and the impact on biological production in the Central and North Pacific 1960-88. Deep Sea Res. $42,1701-1716$.

Rothschild, B.J. and T.R. Osborn, 1988: Small scale turbulence and plankton contact rates. J. Plankt. Res., $10,465-474$.

Welch, D.W., Y. Ishida and K. Nagasawa, 1998: Thermal limits and ocean migrations of sockeye salmon (Onchorhynchus nerka): Long term consequences of global warming. Can. J. Fish. Aquat. Sci., 55, 937-948. 